\title{
EFFECT OF TRIIODOTHYROACETIC ACID ON THE ELECTROCARDIOGRAM IN CRETINISM
}

\author{
BY \\ THOMAS STAPLETON, CHAN GUNN and PAUL GELPKE \\ From the Paddington Green Children's Hospital (Children's Department, St. Mary's Hospital, London, W.2.)
}

(RECEIVED FOR PUBLICATION AUGUST 24, 1959)

The purpose of this note is to report the effect of the acetic acid derivative of triiodothyronine (Triac) on the electrocardiogram (E.C.G.) in cretinism. It is well recognized that myxoedema in the adult and cretinism in the infant lead to an abnormal E.C.G. characterized by a low voltage curve, particularly affecting the $T$ waves, and prolongation of the Q-T interval. On treatment with thyroid these changes disappear. Evans (1956) writes that the E.C.G. becomes normal after three weeks' therapy and that 'the adequate dosage of thyroid may be estimated from watching it reinstate and maintain a normal cardiogram'.

1-3: 5: 3-Triiodothyroacetic acid has an immediate effect on the basal metabolic rate and body temperature in hypophysectomized rats (Donhoffer, Várnai and Sziebert-Horváth, 1958). It has a rapid effect on the basal metabolic rate in myxoedema (Trotter, 1955). Ibbertson, Fraser and Alldis (1959) have shown that it causes a rapid change towards normal in the E.C.G. of adults with myxoedema. They also state that 'in a 5-month-old cretin, at eight hours after $0.5 \mathrm{mg}$. of triac by mouth, there was an obvious increase in the $R$ and $T$ waves of the E.C.G.'. The effect on the E.C.G. in two infants with cretinism is recorded in this paper.

\section{Case Reports}

Case 1. This boy was seen at the age of 12 weeks. He was the second child of a $\mathrm{Rh}$ positive mother, the other child being a boy aged 16 months who was alive and well, and had no jaundice at birth. The mother had an antepartum haemorrhage one month before delivery. The baby was born three weeks before the expected date of delivery with a birth weight of $4 \mathrm{lb} .13 \mathrm{oz}$. He was breast fed for four weeks and then fed on Ostermilk. The baby had been slightly jaundiced since the second or third day of life, but the stools had always been rather light yellow in colour. The urine had always been dark.
On examination the baby had a rather harsh cry, moderate jaundice of the skin and conjunctivae, an umbilical hernia, and small right and left inguinal herniae. The liver was palpable two finger breadths below the costal margin and the tip of the spleen was palpable. The skin was rather dry, scaly and greasy, especially over the face, and the tongue protruded (Fig. 1). Blood pressure was $70 \mathrm{~mm}$. systolic by the flush method.

The child weighed $10 \mathrm{lb} .3 \mathrm{oz}$. $(4 \cdot 625 \mathrm{~kg}$.), length 21 in. $(53 \cdot 3 \mathrm{~cm}$.).

Haemoglobin was $12 \mathrm{gm} . \%$, reticulocytes $4 \%$.

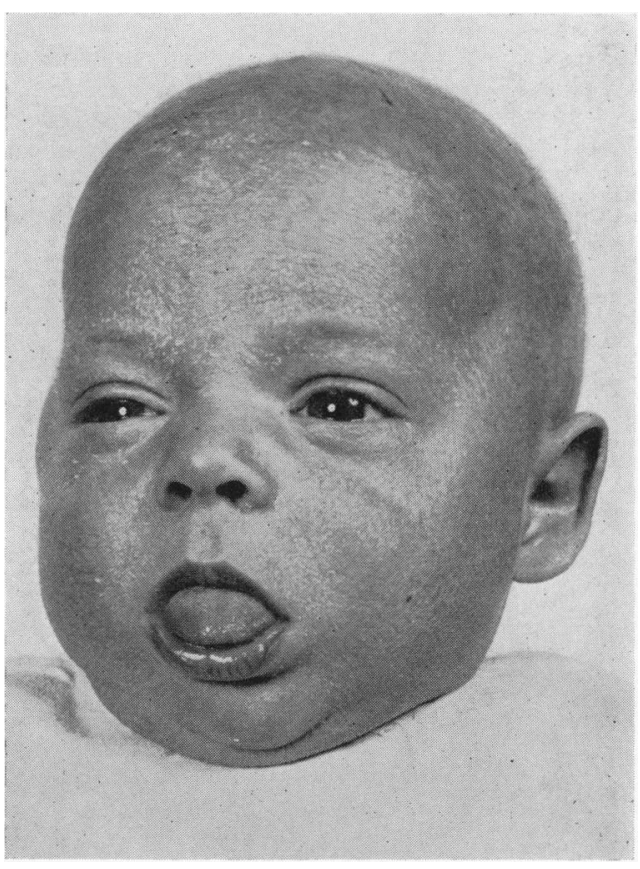

Fig. 1.-Case 1. 


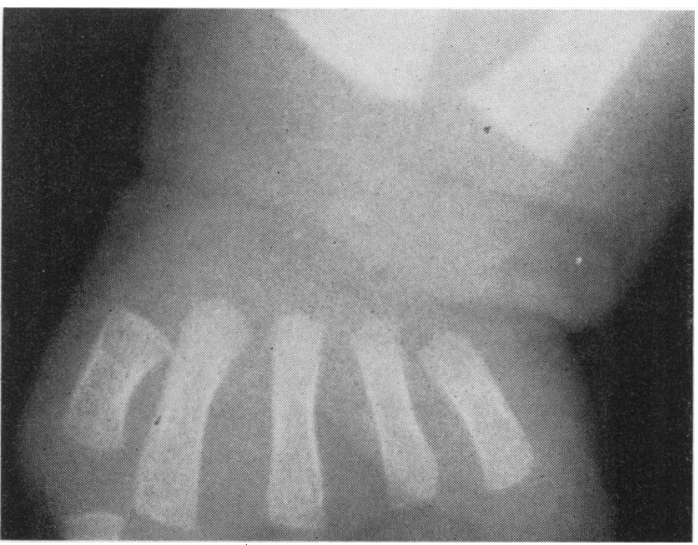

Fig. 2.-Case 1, aged 12 weeks. Radiograph of wrist.

\section{Case I}

Lead II
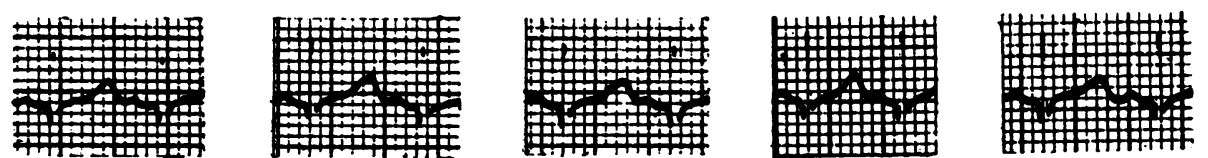

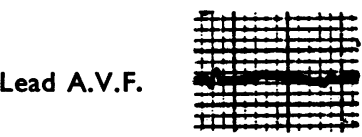

Before

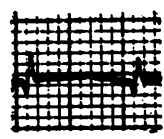

4 hrs.

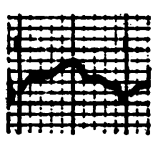

8 hrs.

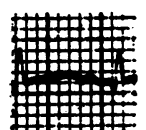

12 hrs.

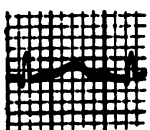

20 hrs.

FIG. 3.-Case 1. E.C.G.s before and after Triac (1 mg. given twohourly for four doses). Timings are in hours after first dose.

FIG. 4.-Case 1, aged 12 months. Radiograph of wrist.

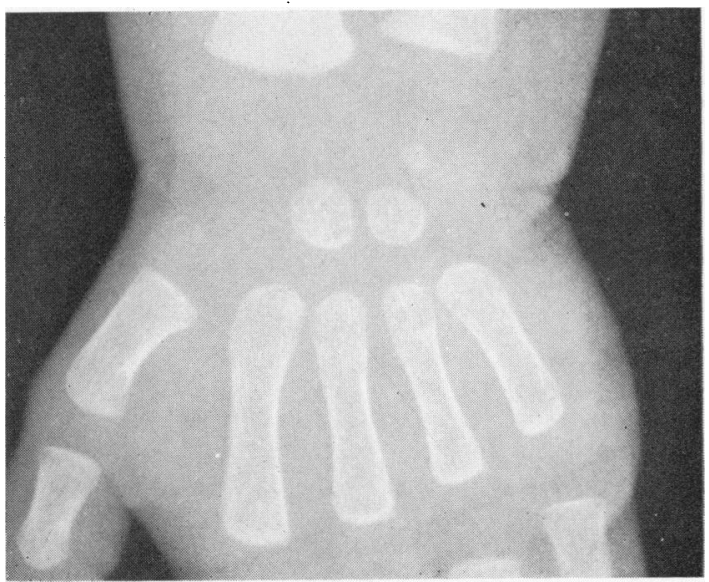


Radiographs showed a retarded bone age (Fig. 2) and a poorly formed first lumbar vertebra.

The clinical diagnosis of cretinism was clear.

Triac was given in 1-mg. doses at two-hourly intervals for four doses. E.C.G.s were recorded before and after, the timings being given from the time of the first dose (Fig. 3).

Response to treatment with thyroid extract B.P. confirmed the diagnosis of cretinism, clinical and radiological (Fig. 4), progress being normal during the following year.

Case 2. This girl was first seen at the age of 6 months. She was the first child, born at full term after a normal pregnancy, the birth weight being $6 \mathrm{lb} .12 \mathrm{oz}$. From the age of $4 \frac{1}{2}$ months she was noticed to be sluggish, sleeping excessively and not to be making progress. On examination she was an obvious cretin (Fig. 5). Radiographs showed a retarded bone age and poor development of the upper part of the body of the second lumbar vertebra (Fig. 6).

This patient was given $4 \mathrm{mg}$. Triac in one dose. E.C.G.s were recorded before and after the test dose (Fig. 7).

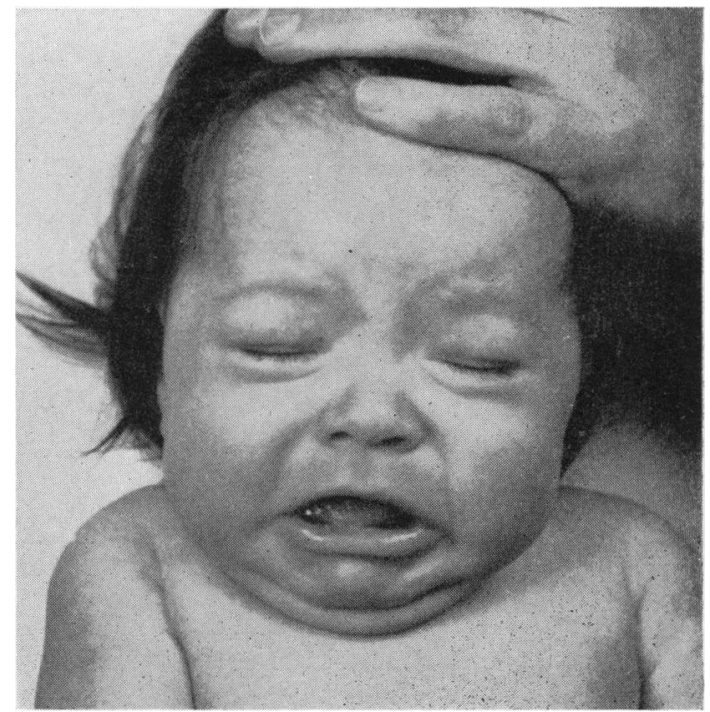

Fig. 5.-Case 2.

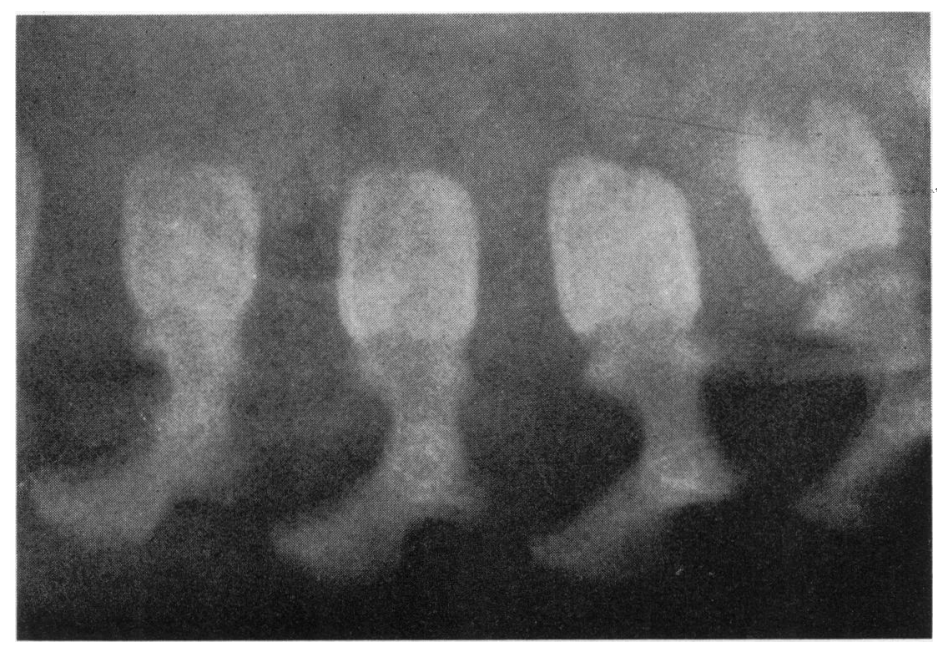

FIG. 6.-Case 2, aged 6 months. Lateral radiograph of lumbar spine.

Response to treatment with thyroid extract B.P. confirmed the diagnosis of cretinism and progress over the next six months was normal.

Normal Infants. A 4-mg. dose of Triac has been given to each of three infants with no endocrine disorder and a normal E.C.G. pattern. Small variations in the magnitude of the complexes were found on successive recordings even when great care was taken over standardization. There were, however, no changes in voltage comparable in magnitude to that observed in Case 2 described above. 
Case 2
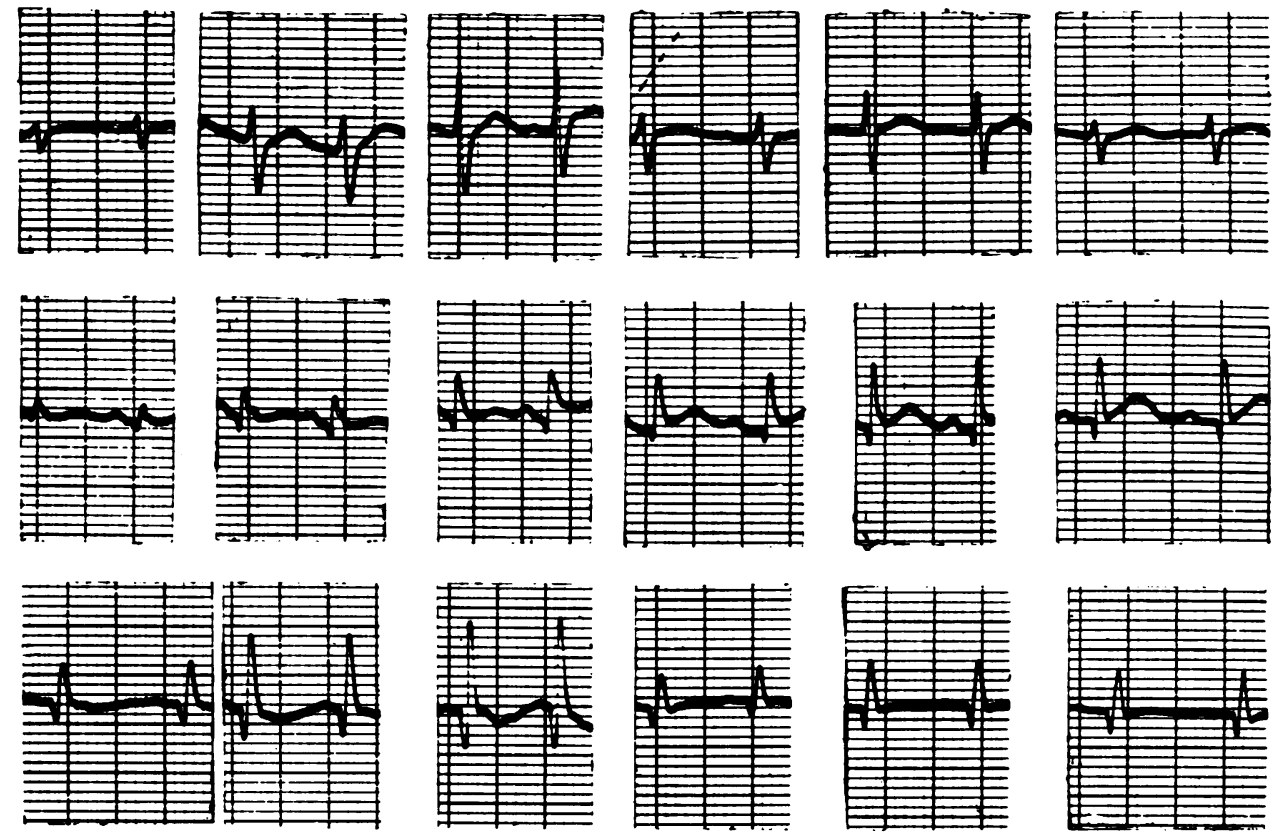

AVR
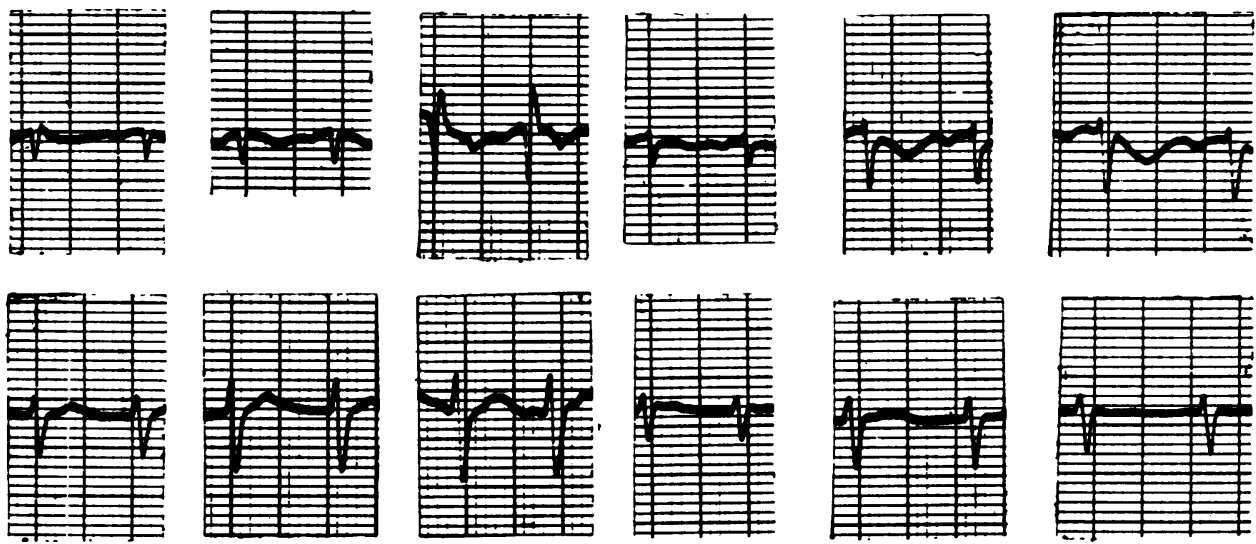

AVF

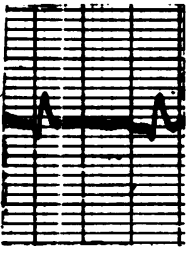

Before

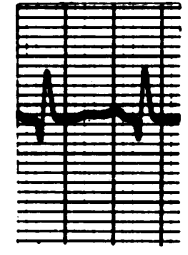

3 hrs.

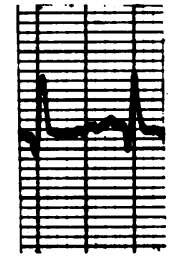

$6 \mathrm{hrs}$.

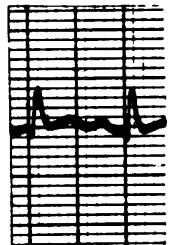

9 hrs.

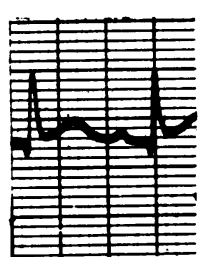

24 hrs.

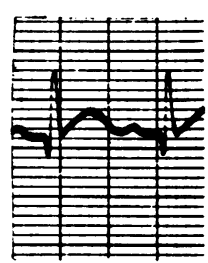

48 hrs.

Fig. 7.-Case 2. E.C.G.s before and after Triac ( $4 \mathrm{mg}$. given in one dose). Timings are in hours after administration of Triac. 


\section{Comment}

Care was taken to ensure that the standardization of the E.C.G. machine* was correct and similar for each tracing. The main change noted in the E.C.G.s of cretins was an increase in the voltage. The response was not as marked in the first patient, to whom the triiodothyroacetic acid was given in divided doses over a six-hour period, as in the second patient, to whom a large single dose was given. In the latter case the response was unequivocal; the E.C.G. did not return completely to its previous low voltage pattern even after three days. Whether this test will be of significant value in the diagnosis of less obvious cases of cretinism is doubtful since in them the initial electrocardiogram will often not be significantly abnormal.

\footnotetext{
* Cambridge Electrite Model Portable Electrocardiograph.
}

\section{Summary}

The effect of triiodothyroacetic acid on the electrocardiogram in cretinism is described.

We are grateful to Professor Russell Fraser for his comments and for the supply of Triac given to the first patient, and to Dr. A. Generowicz for the recordings on the infants with no endocrine disorder.

\section{REFERENCES}

Donhoffer, S. Várnai, I and Sziebert-Horváth, E. (1958). Immediate effect of 1-3:5:3'-Tri-iodothyroacetic acid on metabolic rate and body temperature in hypophysectomized rats and the actions of body temperature in hypophysectom

Evans, W. (1956). Cardiology. 2nd ed. Butterworth, London. Ibbertson, K., Fraser, R. and Alldis, D. (1959). Rapidly acting thyroid hormones and their cardiac action. Brit. med. J., 2, 52.

Trotter, W. R. (1955). Effect of Triiodothyroacetic acid in a case of myxoedema. Lancet, 2, 374. 